\title{
Experimental evidence that livestock grazing intensity affects cyclic vole population regulation processes
}

\author{
Nacho Villar • Thomas Cornulier • Darren Evans • \\ Robin Pakeman $\cdot$ Steve Redpath $\cdot$ Xavier Lambin
}

Received: 3 October 2012/ Accepted: 15 August 2013/Published online: 8 September 2013

(c) The Author(s) 2013. This article is published with open access at Springerlink.com

\begin{abstract}
Grazing by domestic ungulates may limit the densities of small herbivorous mammals that act as key prey in ecosystems. Whether this also influences density dependence and the regulation of small herbivore populations, hence their propensity to exhibit multi-annual population cycles, is unknown. Here, we combine time series analysis with a large-scale grazing experiment on upland grasslands to examine the effects of livestock grazing intensity on the population dynamics of field voles
\end{abstract}

Electronic supplementary material The online version of this article (doi:10.1007/s10144-013-0398-x) contains supplementary material, which is available to authorized users.

N. Villar · T. Cornulier $\cdot$ X. Lambin $(\square)$

School of Biological Sciences, Zoology Building, University of Aberdeen, Tillydrone Avenue, Aberdeen AB24 2TZ, Scotland, UK

e-mail: x.lambin@abdn.ac.uk

N. Villar

e-mail: nachoprad@gmail.com

T. Cornulier

e-mail: cornulier@abdn.ac.uk

\section{N. Villar $\cdot$ S. Redpath}

ACES-Aberdeen Centre for Environmental Sustainability, University of Aberdeen, 23 St Machar Drive, Aberdeen AB24

3UU, Scotland, UK

e-mail: s.redpath@abdn.ac.uk

N. Villar · R. Pakeman

The James Hutton Institute, Craigiebuckler, Aberdeen AB15

$8 \mathrm{QH}$, Scotland, UK

e-mail: robin.pakeman@hutton.ac.uk

\section{Evans}

Department of Biological Sciences, University of Hull, Cottingham Road, Hull HU6 7RX, England, UK

e-mail: d.evans@hull.ac.uk
(Microtus agrestis). Using log-linear modelling of replicated time series under different grazing treatments, we show that increased sheep densities weaken delayed density dependent regulation of vole population growth, hence reducing the cyclicity in vole population dynamics. While population regulation is commonly attributed to both topdown and bottom up processes, our results suggest that regulation of cyclic vole populations can be disrupted by the influence of another grazer in the same trophic level. These results support the view that ongoing changes in domestic grazing intensity, by affecting small mammal dynamics, can potentially have cascading impacts on higher trophic levels, and strongly influence the dynamics of upland grassland systems.

Keywords Density dependence $\cdot$ Field vole Microtus agrestis · Grasslands · Herbivory · Population cycles $\cdot$ Ungulate grazing

\section{Introduction}

Grassland ecosystems in many parts of the northern hemisphere are dominated by pulses in the abundance of key herbivores, such as vole population cycles, with large impacts across trophic levels (Ims and Fuglei 2005). Where grasslands are managed for livestock grazing, changes in land use through land abandonment in marginal areas (an ongoing pattern in Europe and North America) or agricultural intensification (a pattern in much of Asia) may impact on key small mammal herbivores with potential ecosystem-wide impacts (Food and Agriculture Organisation 2006; Smith et al. 2007). Increased domestic ungulate grazing reduces the density of small mammal herbivores with whom they compete for resources through, for 
example, decreased food and cover, increased exposure to predators and/or decreased nesting and burrowing sites (e.g., Steen et al. 2005; Evans et al. 2006; Torre et al. 2007 and references therein). However, whether such changes also affect small mammal herbivore population regulation processes and propensity to exhibit multi-annual cycles is not known.

Autoregressive log-linear modelling of time series of vole dynamics strongly suggests that cyclic dynamics arise from a combination of direct and delayed density dependent influences on population growth rate (Bjørnstad et al. 1995). Classically, trophic interactions, in particular predator-prey interactions, are invoked as the likely processes underpinning delayed density dependence, and hence are deemed responsible for multi-annual cycles (Korpimäki and Krebs 1996; Hanski et al. 2001). However, much of the supportive evidence derives from time-series approaches, and hence suffers from its correlative and retrospective nature (Lambin et al. 2002). For instance, interpretations of geographical gradients in the density dependence structure of vole population cycles are a high profile case where multiple plausible explanations might fit the same observed pattern (e.g., Bjørnstad et al. 1995; Erb et al. 2000; Saitoh et al. 2003). Thus, arguably, causal interpretation of variations in the density dependence structure observed over time or space are, necessarily, ambiguous in the absence of experimental validation (Stenseth 1999).

Experiments are better suited to establish causation, but are challenging in the context of cycles because of the financial and logistical difficulties of conducting and replicating them over relevant spatial and temporal scales, ideally requiring landscape-scale and multi-annual experiments. Furthermore, even large-scale field-based experimental manipulation can be strongly influenced by the surrounding landscape matrix, potentially masking underlying results. For example, food supplementation and predator exclusion treatments applied over exceptionally large $1 \mathrm{~km}^{2}$ (100 ha) experimental areas in the Kluane Project (Yukon, Canada) affected snowshoe hare (Lepus americanus) demographic rates but failed to prevent decline phase cycles because of movements between experimental plots and the surrounding taiga forest (Krebs et al. 1995). Similarly, Ims and Andreassen (2000) found that vole population growth rates in a set of 7 experimental plots covering 0.5 ha each were synchronised with the regional un-manipulated surroundings of the experimental set up through a feedback loop between avian predation and vole dispersal.

In practice there remains a need for methods that allow the better combination of time series approaches and experimental studies in order to isolate any causal relations without loss of generality. Here, we use time series from a unique, large-scale, replicated grazing experiment conducted in a grassland system where grass and herb-eating field voles undergo cyclic fluctuations in order to test the hypothesis that the grazing intensity of domestic ungulates impacts upon vole dynamics. We demonstrate the use of log-linear autoregressive models of experimental time series in order to derive density dependent parameters used as statistical descriptors or "probes" (Kendall et al. 1999) that allow us to examine this interaction between herbivores. In addition, we discuss potential mechanisms that may account for our results in face of current interpretations of density dependent parameters in vole cycles and recent empirical results, and discuss their relevance on the context of interactions between herbivores and livestock grazing in grassland systems.

\section{Materials and methods}

Field methods

A grazing experiment was established at Glen Finglas, Scotland $\left(56^{\circ} 16^{\prime} \mathrm{N}, 4^{\circ} 24^{\prime} \mathrm{W}\right)$, in 2002 using $24 \times 3.3$ ha plots in an acidic grassland habitat, dominated by Molinia caerulea-Potentilla erecta mire, Juncus effusus/acutiflorus-Galium palustre rush pasture and Festuca ovina-Agrostis capillaris-Galium saxatile grassland communities (Dennis et al. 2005). 2002 was used as baseline year, and in 2003 we applied four grazing treatments, with six replicated and randomized plots per treatment (replicates hereafter referred as "blocks") distributed across an altitudinal gradient $(220-500 \mathrm{~m}$ above sea level) in three clusters with two adjacent blocks each (further details in Evans et al. 2006). Plots were divided by livestock proof wire fences. The grazing treatments mimic realistic management conditions commonly implemented in Scotland (Scottish Agricultural College 2008): $\mathrm{T} 1=2.7 \mathrm{ewes} \mathrm{ha}^{-1}$; $\mathrm{T} 2=0.9$ ewe $\mathrm{ha}^{-1} ; \mathrm{T} 3=$ ungrazed, which correspond to commercial, conservation and abandonment grazing levels respectively. Sheep grazing took place from March until October every year to follow current management practices. A fourth treatment, a mix of cattle and sheep grazing with the same grazing offtake as $\mathrm{T} 2$, was also included in the experiment in order to inform management policies, but was not used in the elaboration of this manuscript because it did not provide useful extra information about the impact of grazing intensity on vole dynamics [see Fig. S1 in Electronic Supplementary Material (ESM)]. Apart from enforcing different livestock densities, treatments in our experiment suffered from no other experimental input of any kind, including mowing, burning, supplemental feeding or plant harvesting or any kind of management or manipulative activity. 
We estimated field vole abundance using an index based on vole signs collected biannually (March and October 2002-2009). Each plot had a regular, square grid of 25 sampling points $40 \mathrm{~m}$ apart of which five were randomly selected and each sampled with five $25 \mathrm{~cm} \times 25 \mathrm{~cm}$ quadrats thrown randomly within a radius of approximately $5 \mathrm{~m}$ and the presence of fresh (green and un-oxidised) grass clippings or droppings recorded (Evans et al. 2006). In March 2005 we missed one census due to logistical reasons, and a more intensive sampling regime with three quadrats at each of the twenty-five points in the regular grid was additionally implemented during 2006-2008.

\section{Statistical analyses}

In order to estimate density dependent parameters of vole population growth rates we fitted a seasonal log-linear auto-regressive model (Hansen et al. 1999), where the proportion of quadrats yielding positive vole signs were used as a proxy for density (Lambin et al. 2000). Observation error may cause bias in the estimation of densitydependence. A Bayesian state-space model can be used to account for observation error by combining the system process with an observation process that describes the statistical relationship between the observation and the unknown true density that would be measured under infinite sampling effort (Stenseth et al. 2003).

\section{System process}

Let $S_{i, j, t}$ and $F_{i, j, t}$ be the Spring and Autumn log abundances of voles in block $i$ and treatment $j$ in year $t$. We used a version of the seasonal log-linear auto-regressive model of Hansen et al. (1999) adjusted to our experimental design and non-centred data to model the population growth rates in winter and summer (Eq. 1a and 1b, respectively), as follows:

$$
\begin{aligned}
S_{i, j, t}-F_{i, j, t-1}= & a_{0, j}+a_{1, j} F_{i, j, t-1}+a_{2, j} S_{i, j, t-1}+a_{3, j} F_{i, j, t-2} \\
& +a_{4, j} S_{i, j, t-2}+\gamma_{1, i, j, t}+\gamma_{2, i}
\end{aligned}
$$$$
F_{i, j, t}-S_{i, j, t}=b_{0, j}+b_{1, j} S_{i, j, t}+b_{2, j} F_{i, j, t-1}+b_{3, j} S_{i, j, t-1}
$$$$
+b_{4, j} F_{i, j, t-2}+\eta_{1, i, j, t}+\eta_{2, i}
$$

The index $j=1,2,3$ denotes the experimental treatment. $\gamma$ and $\eta$ are hierarchical Gaussian errors for the observation- and block-level random effects, respectively.

Annual population growth rates $\left(R_{t}\right)$ can be expressed in relation to autumn densities as:

$R_{i, j, t}=\Omega_{1, j} F_{i, j, t-1}+\Omega_{2, j} F_{i, j, t-2}$, where the annual direct $\left(\Omega_{1, j}\right)$ and delayed $\left(\Omega_{2, j}\right)$ densitydependence parameters can be derived from the seasonal model using: $\Omega_{1, j}=a_{1, j}+b_{1, j}+a_{2, j}+b_{2, j}+a_{1, j} b_{1, j}$ and $\Omega_{2, j}=a_{3, j}+b_{3, j}+a_{4, j}+b_{4, j}+a_{1, j} b_{3, j}+a_{3, j} b_{1, j}-$ $a_{2, j} b_{2, j}$.

\section{Observation process}

The number $O b s_{i, j}$ of quadrats with vole signs in the plot $(i, j)$ in year $t$ and season $k$ follows a $\operatorname{Binomial}\left(p_{i, j, t, k}, N_{i, j, t, k}\right)$ distribution with a probability of sighting per quadrat $p_{i, j, t, k}$ and a number of quadrats sampled $N_{i, j, t, k}$. The unknown vole abundances were then related to $p_{i, j, t, k}$ using a complementary log-log link which is similar to the log-link assumed in the autoregressive log-linear model for the range of sighting probabilities encountered, but prevents estimated probabilities from exceeding values above one. In this state-space framework, missing values from spring 2005 were estimated as a by-product of the model fitting process, hence they didn't contribute to inform about model fit. Earlier calibration work established that volesign detection probability is linearly related to vole density estimated by live-trapping (Lambin et al. 2000), and it is also known that the log-linear model fitted has some robustness to non-linearities in the proxy for density (Tkadlec et al. 2011).

We used independent uninformative priors for all the parameters of the model. The model was fitted with OpenBUGS 2.2.0 (Lunn et al. 2009). The model, data and further detail are given in ESM.

\section{Results}

The intensity of sheep grazing had an effect on density dependent parameters, hence on predicted vole population dynamics according to log-linear autoregressive models. The vole abundance time series in the ungrazed treatment (T3) showed patterns typical of multi-annual cyclic dynamics, but at the higher sheep densities vole dynamics became less cyclic (Fig. 1). The density dependence regulation of vole population growth decreased (i.e., tended towards more positive values) with increasing grazing intensity (Fig. 2), but the magnitude of this change was much larger and only statistically significant on the delayed density dependent component (difference in $\Omega_{2}$ between treatments 1 and 3 was $0.676,95 \%$ credible interval 0.094-1.282, all other differences overlapping 0, see Table $\mathrm{S} 1$ in ESM). The combination of estimated direct and delayed density dependence parameters in the absence of sheep grazing (T3) predicts large amplitude cycles with a 3 year-period (Fig. 2); a dampening of the cycle's 
Fig. 1 Time series of vole sign indices (VSI) recorded during 2002-2009 under different experimentally imposed grazing intensities. Different line types and symbols represent different replicates. Treatment $1=2.7$ ewes ha ${ }^{-1}$, Treatment $2=0.9$ ewe ha ${ }^{-1}$, Treatment $3=$ ungrazed. There was no survey in 2005 due to logistical reasons

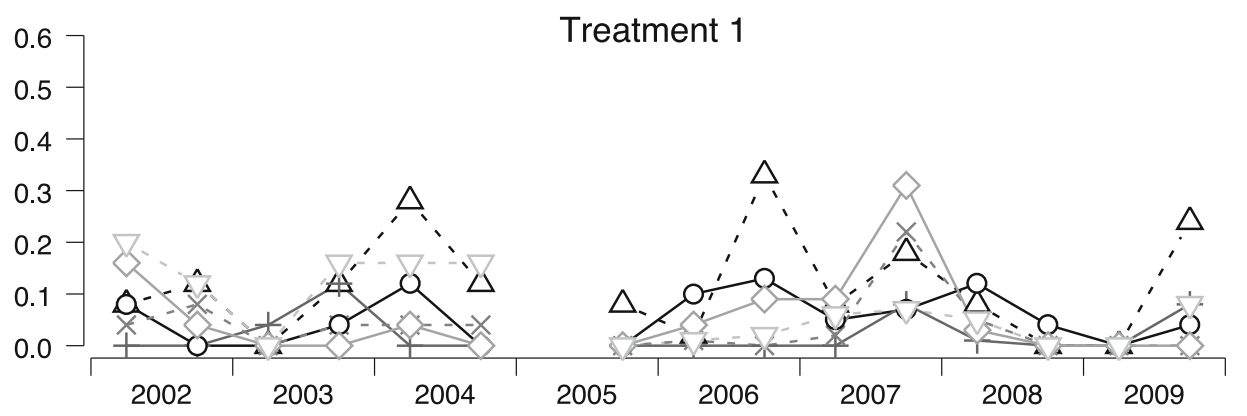

Treatment 2
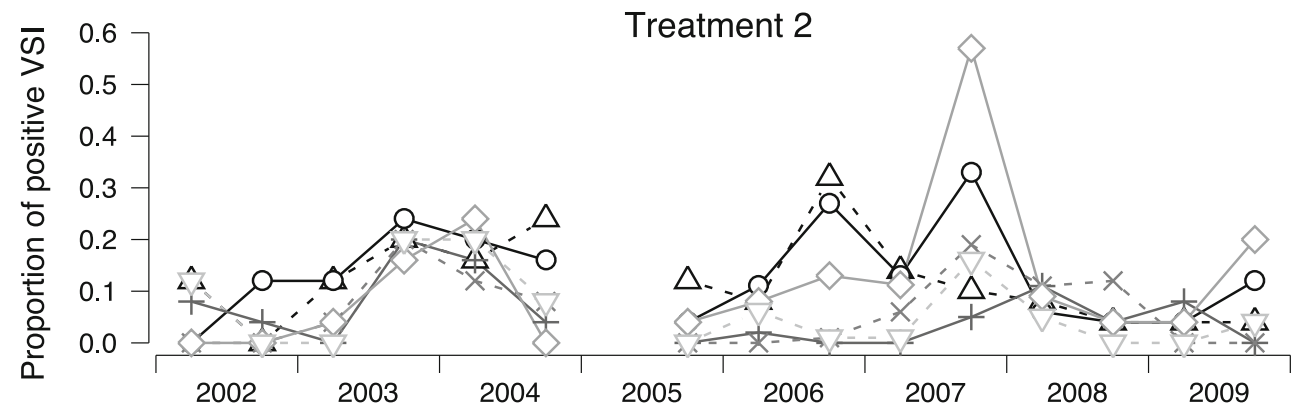

Treatment 3

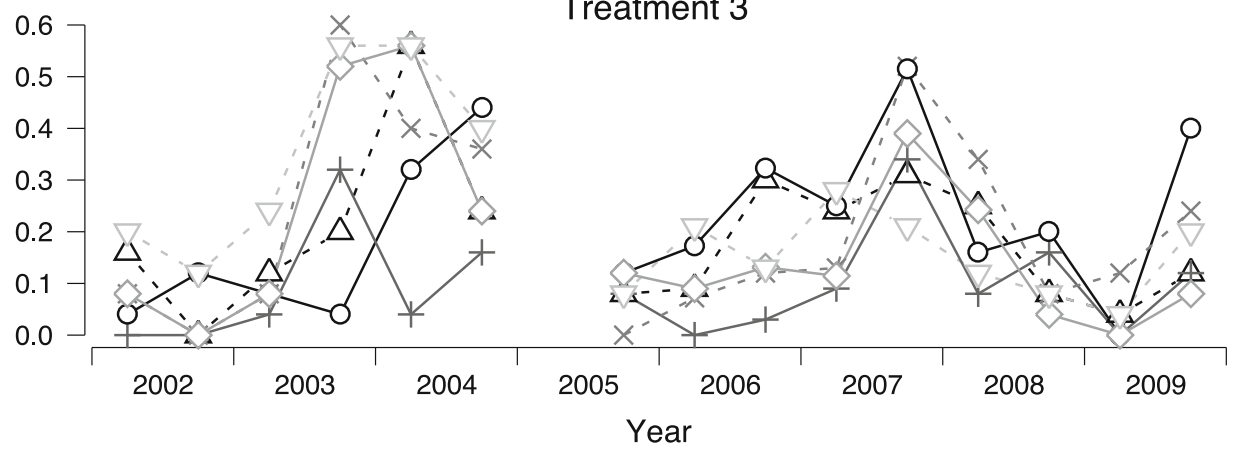

amplitude without change in the periodicity at intermediate grazing levels (T2) and the loss of cyclicity at the highest grazing levels (T1), matching trends observed in the time series.

\section{Discussion}

Fitting log-linear state-space models to time series of vole abundance indices from a replicated sheep grazing experiment revealed that in addition to affecting mean vole density (Evans et al. 2006), grazing by domestic ungulates also impacts upon vole dynamics, leading to a loss of cyclicity at high grazing density. Though this technique did not allow us to pinpoint the exact causal chain that generated a change in vole dynamics, the combination of experimental approach (including manipulation and replication, and control of all other factors by virtue of experimental randomisation) and time series analysis allowed us to identify delayed density dependence as the regulatory process affected by livestock grazing with little evidence of direct density dependence being affected. As such, combining time series analysis with a factorial experiment is a methodological step forward relative to previous attempts to link density dependent parameters (probes) to unmanipulated environmental covariates, such as latitude and seasonality (e.g., Bjørnstad et al. 1995; Erb et al. 2000; Saitoh et al. 2003). Another relevant aspect of the method is that, despite time series being relatively short (8 years), the combination of a randomized, replicated large-scale experimental set up with a state-space analytical model was essential to obtain estimates of probes with greater precision and less bias than hitherto feasible (e.g., Hansen et al. 1999; Stenseth et al. 2003).

On the other hand, despite using a seasonal model, identifying the seasonal time lag at which density dependence was largest cannot be done reliably, in spite of suggestions to the contrary (Hansen et al. 1999). This is 


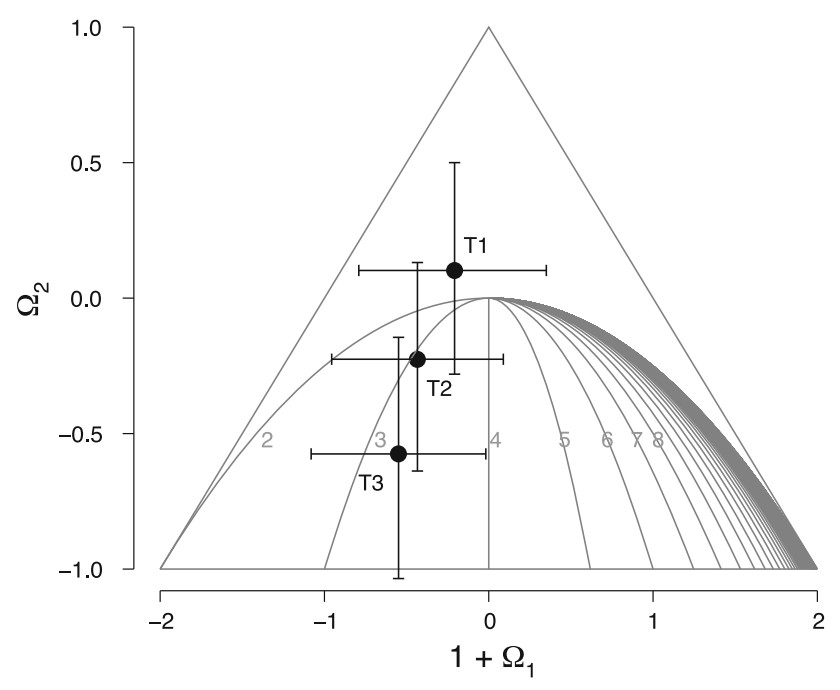

Fig. 2 Effect of grazing intensity on direct $\left(\Omega_{1}\right)$ and delayed $\left(\Omega_{2}\right)$ density dependent regulation of field vole population growth, with $95 \%$ posterior credible intervals. $\mathrm{T} 1=2.7$ ewes ha $^{-1}, \mathrm{~T} 2=0.9$ ewe $\mathrm{ha}^{-1}, \mathrm{~T} 3=$ ungrazed. The parameter space described by Royama (1992) indicates unstable dynamics outside the triangle, stable dynamics with dampened oscillations inside the triangle and above the parabola, and cyclic dynamics inside the parabola (cycle period length in years is given by grey numerals)

because the seasonal auto-regressive model suffers from high serial correlation between parameters (details in ESM). The use of this model nevertheless enabled us to use data from biannual sampling occasions and our inference is based on summary annual parameters which were not affected by the issue of parameter identification.

Several authors have suggested that ungulate trampling reduces the densities of small mammals by decreased availability and larger destruction of vole nesting and burrowing sites (e.g., Steen et al. 2005; Evans et al. 2006; Torre et al. 2007 and references therein). However, it is far from clear how this mechanism would affect delayed density dependence, since, to our best knowledge, even its impact on small mammal density has never been quantified. Instead, classical interpretations of delayed density dependence in cyclic vole populations include predatorprey and parasite-host, plant-herbivore interactions, as well as trans-generational effects (Stenseth and Ims 1993; Korpimäki and Krebs 1996). Plausible interactions between livestock grazing and some of these mechanisms are numerous, but some are more intuitive than others. For example, there's no empirical evidence supporting a relationship between ungulate grazing and trans-generational effects in voles. Indirect effects of grazing on landscape structure and connectivity might influence macro-parasite prevalence and transmission (Brownstein et al. 2005; Halos et al. 2010), so that grazing intensity and vole parasitism might be linked. Grazing impact on landscape structure and connectivity might also have influenced predator foraging opportunities, e.g., by increasing avian predation or decreasing risk-averse mustelid foraging behaviour (Zub et al. 2008), conceivably leading to a net reduction in delayed density dependence (Bjørnstad et al. 1995; Hanski et al. 2001). Predation would be expected to have synchronised cycles of adjacent prey populations, as shown in microcosm experiments (Vasseur and Fox 2009) and field experiments involving small mammals (Korpimäki and Krebs 1996; Ims and Andreassen 2000). Thus under a predation hypothesis we would have expected that strong prey depletion by mobile predators would have swamped the differences between experimental treatments. Yet, we found a clear treatment effect. However, as is evident from Fig. 1, there was a degree of synchrony shared between plots with different experimental treatments but contiguous to each other e.g., in the same "block". Hence we cannot rule out entirely the influence of predation as an important factor contributing to the strong influence of ungulate grazing intensity on vole dynamics. Thus, our results point towards a local process generating delayed density dependence which was sufficiently spatially restricted in its influence so as to be unable to synchronise vole dynamics in different treatments.

Recent work suggests that vole grazing of grasses cause changes in plant quality through induction of plant defences. Several grass species found in acidic uplands uptake silica after sustained vole grazing, and such a process has the potential to cause delayed density dependence in vole populations (Reynolds et al. 2012). However, our results show a reduction in delayed density dependence with increasing sheep grazing intensity, which goes in the opposite direction than predicted if sheep grazing contributed to changes in grass quality either through increased silica induction or by depletion of silica-poor palatable grasses. It remains possible, however, that ungulate grazing might have led to an increase in the abundance of grass species that are grazing tolerant versus those producing delayed inducible defences (Augustine and McNaughton 1998). Alternatively, depletion of plant biomass by grazing in spring and summer may have reduced the degree of seasonality in plant availability to voles, which is a key factor in the propensity of populations to display cycles (Stenseth et al. 2003; Smith et al. 2006; Reynolds et al. 2012). Specific studies with explicit measurements of plant quality and biomass, as well as parasitism and predation, would be required to identify the specific mechanisms involved, most adequately those of an experimental nature.

Given the removal of plant biomass and productivity, it was surprising that neither the baseline population growth rate (intercept) nor direct density dependence $\left(\Omega_{1}\right)$ influence on vole population growth were significantly affected by grazing intensity. According to classical interpretations, this suggests that livestock grazing did not affect intrinsic 
vole population regulation processes, such as territoriality or intra-specific competition.

While these considerations raise important questions about the interpretation of vole dynamics, it is important to bear in mind their relevance in the context of herbivoreherbivore interactions. Irrespective of the specific mechanism responsible for delayed density dependence in vole dynamics, we demonstrated that, in addition to top-down and bottom up processes (Sinclair and Krebs 2002), interactions between herbivores can also modify the density dependence structure, hence population regulation of at least one of the species involved. Previous studies have shown that both competition and facilitation between ungulates and small mammals occur in grassland systems of the northern hemisphere (Steen et al. 2005; Evans et al. 2006; Ims et al. 2007; Torre et al. 2007), and here we demonstrate that such interactions affect population regulation and propensity to cycle of small mammals at grazing regimes commonly implemented in Scotland (Scottish Agricultural College 2008). Thus, we propose that land use changes such as grazing intensification or abandonment might lead to changes in small mammal population dynamics in upland grasslands where pulses of abundance of these herbivores are of foremost importance (Ims and Fuglei 2005), whose impact might propagate across the ecosystem.

Acknowledgments We thank our colleagues who helped in collecting this data, Nigel G. Yoccoz and Bob O'Hara for useful comments on our analysis, the Woodland Trust for logistic support, and Scottish Government's Rural and Environment Science and Analytical Services for funding the experiment. N. Villar was funded by a $\mathrm{PhD}$ studentship awarded by the Aberdeen Centre for Environmental Sustainability; XL, TC and SMRE acknowledge funding from Biodiversa ERA-net NERC grant NE/G002045/1 and a Leverhulme Research fellowship (XL).

Open Access This article is distributed under the terms of the Creative Commons Attribution License which permits any use, distribution, and reproduction in any medium, provided the original author(s) and the source are credited.

\section{References}

Augustine DJ, McNaughton SJ (1998) Ungulate effects on the functional species composition of plant communities: herbivore selectivity and plant tolerance. J Wildl Manag 62:1165-1183

Bjørnstad ON, Falck W, Stenseth NC (1995) Geographic gradient in small rodent density fluctuations-a statistical modelling approach. Proc R Soc B 262:127-133

Brownstein J, Skelly D, Holford T, Fish D (2005) Forest fragmentation predicts local scale heterogeneity of Lyme disease risk. Oecologia 146:469-475

Dennis P, Elston DA, Evans DM, Evans SA, Gordon I, Grant M, Kunaver A, Marquiss M, Mayes B, McCracken DI, Pakeman RJ, Pearce-Higgins J, Redpath SM, Skartveit J, Stephen L, Benton TG, Bryant D (2005) Effects of grazing management on upland bird populations: disentangling habitat structure and arthropod food supply at appropriate spatial scales (GRUB). Final report to Scottish Executive Environment and Rural Affairs Department

Erb J, Stenseth NC, Boyce MS (2000) Geographic variation in population cycles of Canadian muskrats (Ondatra zibethicus). Can J Zool 78:1009-1016

Evans DM, Redpath SM, Elston DA, Evans SA, Mitchell RJ, Dennis P (2006) To graze or not to graze? Sheep, voles, forestry and nature conservation in the British uplands. J App Ecol 43:499-505

Food and Agriculture Organisation (2006) Livestock's long shadow: environmental issues and options. United Nations Food and Agriculture Organisation, Rome. http://www.fao.org/docrep/ 010/a0701e/a0701e00.HTM

Halos L, Bord S, Cotté V, Gasqui P, Abrial D, Barnouin J, Boulouis H-J, Vayssier-Taussat M, Vourc'h G (2010) Ecological factors characterizing the prevalence of bacterial tick-borne pathogens in Ixodes ricinus ticks in pastures and woodlands. App Environ Microb 76:4413-4420

Hansen TF, Stenseth NC, Henttonen H (1999) Multiannual vole cycles and population regulation during long winters: an analysis of seasonal density dependence. Am Nat 154:129-139

Hanski I, Henttonen H, Korpimäki E, Oksanen L, Turchin P (2001) Small-rodent dynamics and predation. Ecology 82:1505-1520

Ims RA, Andreassen HP (2000) Spatial synchronization of vole population dynamics by predatory birds. Nature 408:194-196

Ims RA, Fuglei E (2005) Trophic interaction cycles in tundra ecosystems and the impact of climate change. Bioscience 55:311-322

Ims RA, Yoccoz N, Bråthen K, Fauchald P, Tveraa T, Hausner V (2007) Can reindeer overabundance cause a trophic cascade? Ecosystems 10:607-622

Kendall BE, Briggs CJ, Murdoch WW, Turchin P, Ellner SP, McCauley E, Nisbet RM, Wood SN (1999) Why do populations cycle? A synthesis of statistical and mechanistic modeling approaches. Ecology 80:1789-1805

Korpimäki E, Krebs CJ (1996) Predation and population cycles of small mammals - a reassessment of the predation hypothesis. Bioscience 46:754-764

Krebs CJ, Boutin S, Boonstra R, Sinclair ARE, Smith JNM, Dale MRT, Martin K, Turkington R (1995) Impact of food and predation on the Snowshoe Hare cycle. Science 269:1112-1115

Lambin X, Petty SJ, MacKinnon JL (2000) Cyclic dynamics in field vole populations and generalist predation. J Anim Ecol 69:106-118

Lambin X, Krebs CJ, Moss R, Yoccoz NG (2002) Population cycles: inferences from experimental, modelling, and time series approaches. In: Berryman AA (ed) Population cycles: the case for trophic interactions. Oxford University Press, New York, pp 155-176

Lunn D, Spiegelhalter D, Thomas A, Best N (2009) The BUGS project: evolution, critique and future directions. Stat Med 28:3049-3067

Reynolds J, Lambin X, Massey F, Reidinger S, Sherratt J, Smith M, White A, Hartley S (2012) Delayed induced silica defences in grasses and their potential for destabilising herbivore population dynamics. Oecologia 170:445-456

Royama T (1992) Analytical population dynamics, vol 10. Population and community biology series. Chapman \& Hall, New York

Saitoh T, Stenseth N, Viljugrein H, Kittilsen M (2003) Mechanisms of density dependence in fluctuating vole populations: deducing annual density dependence from seasonal processes. Popul Ecol 45:165-173

Scottish Agricultural College (2008) Farming's retreat from the hills. Rural Policy Centre. http://wwwsacacuk/mainrep/pdfs/ retreatreportpdf 
Sinclair ARE, Krebs CJ (2002) Complex numerical responses to topdown and bottom-up processes in vertebrate populations. Philos Trans R Soc B Biol Sci 357:1221-1231

Smith MJ, White A, Lambin X, Sherratt JA, Begon M (2006) Delayed density-dependent season length alone can lead to rodent population cycles. Am Nat 167:695-704

Smith P, Martino D, Cai Z, Gwary D, Janzen H, Kumar P, McCarl B, Ogle S, O'Mara F, Rice C, Scholes B, Sirotenko O (2007) Agriculture. In: Metz B, Davidson OR, Bosch PR, Dave R, Meyer LA (eds) Climate change 2007: mitigation. Contribution of Working Group III to the Fourth assessment report of the Intergovernmental Panel on Climate Change. Cambridge University Press, Cambridge, United Kingdom and New York, USA, pp 497-540

Steen H, Mysterud A, Austrheim G (2005) Sheep grazing and rodent populations: evidence of negative interactions from a landscape scale experiment. Oecologia 143:357-364

Stenseth NC (1999) Population cycles in voles and lemmings: density dependence and phase dependence in a stochastic world. Oikos 87:427-461

Stenseth NC, Ims RA (1993) The biology of lemmings. Academic Press, London
Stenseth NC, Viljugrein H, Saitoh T, Hansen TF, Kittilsen MO, Bolviken E, Glöckner F (2003) Seasonality, density dependence, and population cycles in Hokkaido voles. Proc Natl Acad Sci USA 100:11478-11483

Tkadlec E, Lisická-Lachnitová L, Losík J, Heroldová M (2011) Systematic error is of minor importance to feedback structure estimates derived from time series of nonlinear population indices. Popul Ecol 53:495-500

Torre I, Diaz M, Martinez-Padilla J, Bonal R, Vinuela J, Fargallo JA (2007) Cattle grazing, raptor abundance and small mammal communities in Mediterranean grasslands. Basic Appl Ecol 8:565-575

Vasseur DA, Fox JW (2009) Phase-locking and environmental fluctuations generate synchrony in a predator-prey community. Nature 460:1007-1010

Zub K, Sonnichsen L, Szafranska PA (2008) Habitat requirements of weasels Mustela nivalis constrain their impact on prey populations in complex ecosystems of the temperate zone. Oecologia 157:571-582 